\title{
A SUPPOSED DISEASE OF QUAHAUGS FROM NEW BRUNSWICK.
}

\author{
By Philip Cox, Ph. D., University of New Brunswick.
}

The Quahaugs, supposed to suffer from some affection or disease, were from Buctouche, N.B., and were studied chiefly at the Biological Station, St. Andrews, in 1914. Buctouche, Kent county, is situated on the estuary of the Buctouche river, there about 200 feet wide, with an average depth of 20 feet at tow water. The population is about 600. The town is not incorporated, but has a board of health which does not allow waste nor objectionable matter to be dumped into the stream nor on the ice in winter. There is no sewerage system, and only two or three private drains enter the river, hence no pollution of the water seems possible in a stream of its volume with a rise and fall of tide of from $2 \frac{1}{2}$ to 4 feet.

Above the town there are extensive marshes, overgrown with weeds and grass, and laid bare generally at low water, and hence much decaying organic matter is swept seaward, rendering the stream quite turbid. The temperature of the flow is apt to run high, for the water, spread out for hours over the marshy flats, has had time to become warmed, especially during midsummer when from $68^{\circ}$ to $70^{\circ} \mathrm{F}$. cannot be unusual; indeed, when tested at $3 \mathrm{p} . \mathrm{m}$. on July 24 , it stood at $70^{\circ}$. Owing to the quantity of fresh water entering the estuary from the upper river and its branches, the salinity is apt to be low, especially at low water and during the spring and early summer when the fresh water is at its maximum.

\section{MANNER OF STORING.}

The hard-shell clams or quahaugs are confined in floating trays 18 feet by 14 feet by 18 inches, made of boards from 4 inches to 6 inches wide with $\frac{1}{2}$-inch spaces, and moored end to end along the shore in several tiers or ranges. This close arrangement, and the very narrow slots, often overgrown and clogged with algæ, are not favourable to a rapid change of water; indeed the force of the tide either way as a factor aiding the change can be barely perceptible beyond the second tray tidewards, and although a slow interchange is always going on, it must be entirely inadequate to the vital needs of such an immense number of shell-fish crowded together in the manner described. An unobstructed flow of water is still more required to offset the injurious effects of the low salinity and high temperature to which they are exposed, often for several months before shipment. This prolonged period of confinement under abnormal conditions must sap the vitality of the animal and render it less resistant to the still more unnatural and trying conditions of transportation and marketing, particularly if the quahaugs were taken from the beds in Máy before they had recruited after a long winter of inactivity.

The trays are usually filled to the depth of from 6 inches to 15 inches, but when arrivals from the fishing grounds are large, and space limited, they are filled to their utmost capacity and readjusted as soon as extra space is available. Three or four days after, they are turned, if the trays are up to their full capacity, with forks of 8 or 9 tines with chisel points, and broken or dead ones are thrown out; but no close examination is made; whatever happens to be seen is rejected, and, as a matter of fact, dead clams and broken shells were more or less in evidence. It was noticed, moreover, that the middle trays-those farthest removed from the effects of the tide either waycontained the most dead quahaugs, which fact may be regarded as a result, at least 
partially, of the very poor water circulation. How often they are turned depends on circumstances; but, as a considerable growth of algæ and much sediment was seen in some of the trays which had not been recently disturbed, probably once a week would be the maximum. The trays are said to be scrubbed and dried at intervals, and one was seen undergoing the process. It was pointed out that the fork with its chisel-pointed tines, used in turning the clams, may do more or less damage to the mantle, protruding siphons, or edges of the valves, but a close inspection of the material sent to the station for study does not bear out this view, though chipped valves were found in a few cases.

MATERIAL AND ITS SOURCES.

The clams thus stored are of one species, Venus mercenaria L., the short-necked or round clam, or quahaug. It occurs on the gulf shores of New Brunswick and Prince Edward Island, chiefly on mixed sand and clay bottoms and at the level of 1 to 5 fathoms below low tide, but its distribution is local, not general, determined by bottom conditions and influences not understood. Though common on some parts of the New England coast south of cape Cod, it does not seem to occur in the Bay of Fundy nor on the Atlantic coast of Nova Scotia, excluded therefrom doubtless by the colder Arctic waters.

The fishery begins in May, extends to the end of June, and reopens in September, the two intervening months, it is believed, covering the period of spawning; but much remains yet to be learned, not only as regards the length of the reproductive season, but of those occult influences which determine the peculiar distribution of the bivalve. All its known beds are for many months covered, more or less, with ice, the temperature falls, and the clam buries itself in the muds, ceases to feed, and necessarily falls off in condition. Just when it emerges from this dormant state and begins to feed is not definitely known, but is supposed to be about the first of May; yet much must depend on weather conditions and the time the ice disappears, for some springs, like that of 1914, are colder and later than usual. Those clams raked in May, then, are likely to be inferior in quality, to be lacking in the vigour and the vitality of later catches, especially those of October, and are not likely to stand storage and shipping conditions as well. The transfer from cold sea-water of average salinity to the warmer river estuary, fresher at that time than at any other time of the year, perhaps, must tax the animal's powers of resistance to a dangerous degree. It would seem that the early May eatch is the largest of the season, for the more remunerative salmon and lobster fisheries are then scarcely under way, and many fishermen are free to rake the clam beds for a time. These large May receipts are stored and kept under the conditions described for some weeks, in some cases two months; and it is somewhat suggestive that most of the shipments to Chicago and New York going bad were either all May fish or were made up in part of that catch. It might be fruitful of good results to this fishery if this were made the subject of a special inquiry. It must be borne in mind, too, that preparation for reproduction and the process itself tax the vigour and vitality of the animal; and development of the generative organs and their elements to a healthy, ripe stage, may depend on recuperation after the trying season of dormancy. Before this is possible, however, the clams are raked, confined, and the natural food supply cut off; an arrest of growth and functional activity ensue, which may seriously affect the health of the clam.

The stock shipped from Buctouche is obtained from beds in the vicinity; from Cocagne, 12 or 15 miles distant; and from Percival and Gulf bays, Prince Edward Island. It is conveyed to the storage grounds in small vessels. the clams being in bags, piled up in the holds or on deck, and from two to four days are required for the passage from the farthest points. 
MANNER OF SIIPPING AND EXTENT OF INDUSTRY.

Formerly the clams were shipped in ordinary grain and feed bags, but, a considerable loss resulting, it was thought well to use a more open sack permitting of freer circulation, and the coarse open "coffee" bag of about $1 \frac{1}{2}$ bushels" capacity is now in vogue. The quahaugs are sorted and classified as large and small, the soundness is, in one establishment, decided by rapping them together, a manner of testing regarded as injurious by the other, which claims that they are killed by even a slight blow. The action does seem a rather violent one, and it is still a matter of doubt if the jar to a creature of such delicate internal structure and loose arrangement of organs and parts does not produce strains and even ruptures more or less fatal, though the firm objecting to it had also consignments to New York and Chicago go bad. The experiments performed at the station and referred to below are certainly not conclusive on the point.

The sacks of clams are placed in tiers, one on top of the other, the box-car is iced at either end, and re-iced whenever necessary during transit, but no provision is made for the ventilation of the sealed car. The temperature at which it is kept could not be ascertained, nor whether it was uniform; but it is fair to assume that clams taken from water at a temperature of from $68^{\circ}$ to $70^{\circ} \mathrm{F}$., stored for a week or more in one at from $45^{\circ}$ to $50^{\circ} \mathrm{F}$., or perhaps less, and then exposed to a temperature of $80^{\circ}$ or upwards at their point of destination, must suffer from such extremes; and, if shipped in a weak and physically reduced condition, many may be expected to die. It will be seen that the experiments made at the station arè decisive on this point.

The want of ventilation referred to and the pressure at.which half or more of the clams are subjected, keeping the valves firmly shut and rendering oxygen utilization nigh impossible, were thought to be important factors; but, in the light of the tests described below, the latter does not seem to be of any importance, at least within the time limits of the experiments, but the former, a condition that should not be ignored.

Two firms, R. O'Leary and Irving \& Son, send annually from Buctouche to the American market, chiefly to Chicago and New York, between 600 and 700 tons, or about two carloads per week, from early in May till the middle of November.

Though there is always a loss, it never assumed the alarming proportions it did this summer, as the following record of shipments to Chicago made by Mr. O'Leary show:-

\begin{tabular}{|c|c|c|c|c|c|c|}
\hline $\begin{array}{l}\text { Date of } \\
\text { Shipment. }\end{array}$ & Quantity. & $\begin{array}{l}\text { Date of } \\
\text { Arrival. }\end{array}$ & Loss. & $\begin{array}{l}\text { Per cent } \\
\text { Loss. }\end{array}$ & $\begin{array}{l}\text { Per cent } \\
\text { Total } \\
\text { Loss. }\end{array}$ & $\begin{array}{l}\text { Max. Temp. Chicago } 24 \\
\text { hours, before and after } \\
\text { date of arrival. }\end{array}$ \\
\hline June 10th.. & $\begin{array}{l}65,000 \text { large. } \\
33,000 \text { sniall . }\end{array}$ & June $16 \ldots$ & $\begin{array}{l}14,600 \text { large. } \\
19,800 \text { small } .\end{array}$ & $\begin{array}{l}22 \frac{1}{2} \\
60\end{array}$ & 35 & \\
\hline & fi3,000 large. & " 23. & 22,500 large. & $\begin{array}{l}36 \\
13\end{array}$ & 29 & $91^{\circ} \mathrm{F}$ \\
\hline July 1st. & 65,000 large. & July 7 . & 8,500 large. & 13 & 10 & $84^{\circ} \mathrm{F}$. \\
\hline 8th.. & $\begin{array}{l}20,000 \text { small . } \\
65,6,00 \text { large. } \\
15,000 \text { small . }\end{array}$ & . 13. & $\begin{array}{c}14,000 \\
\ldots \ldots\end{array}$ & $21 \frac{1}{2}$ & $17 \frac{1}{2}$ & $93^{\circ} \mathrm{F}$. \\
\hline
\end{tabular}

The loss in subsequent shipments was unimportant.

It is seen: (a) that the large clams generally suffered the more; $(b)$ that the small ones were practically immune after June 16 , but the large clams continued to die for a month longer; $(c)$ that other factors than exposure to high temperature at the point of destination were at work, since the cargo arriving June 16 lost more at a temperature of $70^{\circ} \mathrm{F}$., with a mean of $59^{\circ}$ for the $15 \mathrm{th}, 16 \mathrm{th}$, and $17 \mathrm{th}$, than that of July 13 at a temperature of $93^{\circ} \mathrm{F}$., with a mean of $80^{\circ} \mathrm{F}$. for the 12th, 13th, and 14th, though the death-rate of the large was about the same in both. 
6 GEORGE V, A. 1916

The consignees reported the stock diseased, and eventually refused to accept any further consignments, though later on shipping was resumed. The merchants were alarmed, as it meant a big loss and the probable ruin of a growing industry of considerable economic importance, and requested the biological board to investigate the matter. Directed by Professor A. B. Macallum, Toronto Lmiversity, secretary-treasurer of the board, I went to Buctouche, inspected storage and other conditions, and brought away samples of water and lots of clams from several trays for study at the Marine Biological Station at St. Andrews, which were later supplemented by a special lot from one of the firms. They were all transferred to wooden tanks of sea-water, away from direct light, and jets were kept constantly running to renew and aerate it.

It must be noted that the salinity of this water is greater than that of the mooring grounds at Buctouche, where at low tide the specific gravity was only 1.0178 and at high tide 1.0202 , but at the station it registers 1.02425 , which was maintained fairly constant throughout, for the reservoirs supplying the tanks are always refilled at high tide. No ill-effects, however, were perceptible during the three or four weeks the bulk of the stock were thus under observation, which implies that the quahaug possesses a considerable power of resistance to osmotic pressure.

\section{EXAMINATION AND TESTS.}

An extended microscopic examination of the fluids and organs of many was made, but no trace of disease, due to pathological causes, could be found; a finding accentuated by the fact of only one death occurring among the several hundreds kept in the trays. It died the day after its arrival at the station.

It was conjectured, however, that the series of rather sudden changes of temperature from the storage trays at $70^{\circ} \mathrm{F}$. to a sealed box-car at $45^{\circ}$ or $50^{\circ}$ for a week or more followed by $80^{\circ}$ or $90^{\circ} \mathrm{F}$. at the point of destination, might cause a high death-rate of clams kept long in confinement and raked while they were in a reduced condition. To test this, a set of eight were put in the station ice-house for three days in a temperature ranging from $45^{\circ}$ to $48^{\circ}$, and were then exposed to the open air at a mean of $60^{\circ}$, the maximum (one instance) being $72^{\circ}$. At the end of three days all were dead but one, which on dissection showed very feeble signs of life.

Another lot of ten was taken directly. from the trays and exposed for fourteen days in the open air. They were all alive at the end of that time, and were returned to the trays where they still live, August 25.

These experiments seem to confirm the suspicion that sudden alterations of temperature are fatal. It will be seen, too, that in some respects the test was not so severe as the actual shipping. The ice-house is well ventilated; the duration of exposure therein was three days, not seven; and the average and maximum temperature of the weather was less than in Chicago when the last three shipments arrived. The contrast, however, is great-the first lot all died, the second, exposed longer, survived the test. The maintenance of a uniform average temperature during transit and marketing seems all-important.

A lot of ten were "rapped" and exposed for six or seven days, and two died after being returned to the water. Of the eight mentioned above, which were subjected to a low temperature in the ice-house, four had been previously "rapped." While the data, then, are too meagre and uncertain to warrant any general conclusion as to the effects of this means of testing the soundness of clams, some considerations seem to point to it being injurious, and hence it should, if possible, be eliminated.

A general falling-off in weight resulted from all exposures. A lot of ten, wiped carefully, were weighed, and at the end of six days, reweighed. The loss ranged from 8 per cent to 20 per cent, or an average of 12 per cent, and the larger ones invariably showed the greater reduction, the two heaviest, of 220 and 246 grammes, respectively, losing 18 per cent. As no solid matter was excreted, the loss is clearly

* After this had been written I was informed by the shipper that the temperature of the iced car, ten hours after sealing, was $40^{\circ} \mathrm{F}$. 
SESSIONAL PAPER No. 38a

due to evaporation of the contained water or that of the organic fluids, for several check experiments demonstrated that the shell remains constant as long as the contained moisture lasts. It is reasonable to assume that under such conditions, excretion of deleterions gas and secretion of oxygen must decline, and the functional activities of all parts and organs be lowered. The large quahaugs were much less resistant than the small ones, for 90 per cent at least of all dying in the course of the experiments were of that class.

Just here it may be asked: Does not a considerable percentage of old c'ams normally die every season in consequence of expended energy involved in reproduction, a number, the greater as the environment becomes the less natural? Very little is known of this and many other phases of its life-history, and until fuller and more definite knowledge is available, economic problems, like that under discussion, cannot be satisfactorily solved.

When loaded in box-cars, half or more are under a pressure too great to permit the valves to reopen; for, though they are shut and kept closed by contraction of the adductor muscles, they are reopened automatically by the elasticity of a small hinge, too weak, however, to overcome the increased resistance. Hence it was surmised that oxygen utilization would be greatly reduced, fatal results foll $\mathrm{w}$, and in the premises the mortality seemed partially accounted for; but in the light of the following experiments it cannot be regarded otherwise than at best a contributory cause, effective only, if at all, in a high temperature and under faulty ventilation.

August 3, thirteen clams were put under pressure in the laboratory, some in clamps, the rest under heavy weights. At the same time a large one was put into an 1800-c.c. jar of sea-water which had been boiled for half an hour to expel the oxygen. The jar was completely filled, so as to exclude all air, and sealed. It was noticed that the siphons were kept protruding as long as it was confined in the jar. The temperature of the room rose above $70^{\circ}$ on two occasions, the maximum being $72^{\circ}$, the minimum $58^{\circ}$, the mean for the seven days being $622^{\circ}, 61^{\circ}, 61^{\circ}, 65 \frac{1}{2}^{\circ}, 62^{\circ}, 66^{\circ} 66^{\circ}$, or an average mean of $63^{\circ}$. No night temperatures were taken, but they were probably all below $60^{\circ}$. The conditions were certainly very favourable for testing the quahaug's powers of endurance under a fairly uniform temperature, and pointing to a means of minimizing the losses met with in the trade.

August 10 all were released and placed in trays, where they continued to live until removed at the end of the season.

The tests exemplify the clam's great resistance to the lack of oxygen. Philip H. Mitchell (vide Bull. U. S. Bureau of Fisheries, vol. xxxii, 1912) demonstrated by carefully performed experiments that forcibly closed quahaugs did not appreciably use any oxygen, but voluntarily closed ones did. His experiments, however, were conducted in a water medium, and while the valves may be closely enough set to prevent entrance of that oxygen-bearing element, it may be somewhat different in an air medium: Indeed the ridged character of the margins of the valves would seem to make it probable. One of his most important findings, however, is that oxygen utilization increases with the temperature, and that the smaller clams show a relatively greater consumption of oxygen than the larger.

To prove whether ventilation was or was not a valuable factor in provisions for marketing clams, the following experiments were made:-

(1) A tight box holding thirty-two was closed August 12 and kept in that condition till August 19 under the varying temperature of the room, which ranged between $58^{\circ}$ and $70^{\circ}$. Before being opened, a thermometer thrust through a hole, just bored for the purpose, registered $2^{\circ}$ lower than the room. Three clams were dead and five more died during the next two days in the tray to which they had been transferred, making a total loss of 25 per cent.

(2) Another lot of eleven was put into a glass jar, the top being covered with perforated cardboard, and the vessel was set in a tray in 2 inches of water with a jet 
6 GEORGE V, A. 1916

playing on it. The object was to maintain as uniform a temperature as possible. Seventeen days after, all were alive. Records of shippers and experiments performed at the station prove conclusively that large clams are less resistant than small ones. Lot No. 1 was half and half, but lot No. 2 was all large. The contrast between these two tests may be better seen in tabular form as follows:-

\begin{tabular}{|c|c|c|c|c|c|}
\hline Lot. & $\begin{array}{l}\text { No. of } \\
\text { Clams. }\end{array}$ & $\begin{array}{l}\text { No. of days } \\
\text { out of water. }\end{array}$ & Temperature. & No. lost. & Per cent lost. \\
\hline $\begin{array}{l}1 \ldots \ldots \ldots \ldots \\
2 \ldots \ldots \ldots \ldots\end{array}$ & $\begin{array}{l}32 \\
11\end{array}$ & $\begin{array}{r}7 \\
17\end{array}$ & $\begin{array}{l}\text { variable } \ldots . . . . \\
\text { uniform about } \\
62^{\circ} \mathbf{F}^{\prime} . \ldots \ldots \ldots\end{array}$ & 8 & 25 \\
\hline
\end{tabular}
sized.

That ventilation and uniform temperature are essential is here strongly empha-

Those dying in the course of these studies were microscopically examined, but no cause of death could be discovered. The bodies were wasted, parts shrunken, and the whole general appearance that of an animal dying from enervation due to a lack of nourishment. Generally speaking, no ripe generative elements were found, they had either been shed, or failed to develop into large, sound ova or sperm. In some instances, however, ripe ova and sperm did occur in small quantities, sometimes in the reproductive organs, oftener in the branchial chambers, where the ova were breaking down or disintegrating in the midst-of swarms of bacteria and some protozoa.

It is the general belief that the valves of a clam spring apart at death, the adductor muscles relaxing, but such does not seem to be the case, for an immediate examination found decomposition already under way, accompanied with an offensive odour. In the case of such a low organism it does not seem possible to define death as a separate act, for the various parts and organs do not cease their functions simultaneously, and the muscular tissue of the adductors, the strongest in the body, may be the last to do so. In this connection it may be noted that the consignees at Chicagu maintained the clams were dead on arrival, though the valves were unopened, but when opened in the usual way, they were unfit for use.

It is difficult to account for the decomposition of the ova. Though the clam possesses great resistance to a lack of oxygen, ova, especially when fertilized, demand a medium rich in that element, and renewed constantly. Lacking these conditions, the ovum generally dies and begins to decay, and where, as in the clam, it is in close contact with the most delicate and exposed part of the vascular system, certain toxic effects, fatal to the animal, may result. To this cause may be attributed, in part at least, the high death-rate of shipment in July, probably the maximum spawning period. The small clams were then nearly immune, and it is significant that ripe reproductive products were found in only one small individual at the station. Had this class already spawned, or not reached the necessary age and development? This question could not be answered at the station, nor could any definite information on the point be obtained from the scientific literature available. Its determination would be of some economic value to the trade, and conservation of the fishery.

In closing the brief report of this investigation, the following recommendations might seem warranted by the facts disclosed, and some at least could be tried at little extra cost over present methods. The trade should seek, as far as possible, to minimize the general loss, maintain the reputation of its goods on the market, and at the same time prevent the recurrence of such enormous losses as thase met in 1914. 
SESSIONAL PAPER No. $38 a$

RECOMMENDATIONS.

1. That the floating trays be moored in water of greater salinity and lower temperature than that referred to above.

2. That more favourable methods of promoting circulation and change of water in the trays be adopted. These would seem to be:-

(a) Wider and more numeroús slots.

(b) Shallower trays, or present ones filled to about half their capacity.

(c) Mooring in a more open arrangement, so as to utilize the full benefit of the tide.

3. That stock be shipped in the order of its arrival.

4. That cars be ventilated and kept at a fairly uniform temperature, about $62^{\circ} \mathrm{F}$.

5. And that crowding and pressure be avoided as far as possible.

\section{POINTS AWAITING INVESTIGATION.}

In the course of the investigation, some biological questions and considerations were suggested which might, in the interests of the fishery and science, be fully examined and settled. These may be summarized in part:-

(1) At what age and size is the quahaug sexually mature, and do large and small individuals spawn at the same time?

(2) What proportion of the clams of the various sizes die normally every year, and does death generally follow the spawning season?

(3) What is the general effect of the retention of ova in the case of clams kept for some time in the open air?

(4) Comparison at intervals of quahaug raked early in May with those on the native beds to. determine the growth of the reproductive organs of the former, and the general effect of storage. 